\title{
Molluscicidal Activity of Aqueous Extract of Leaves, Stem Back and Roots of Desert date (Balanite Egyptiaca Del.) against common Liver Fluke (Fasciola Hepatica) found in the Snail (Lymnea natalensis)
}

\author{
${ }^{1 *}$ ABDULLAHI, Y ${ }^{2}$ MUHAMMAD, I; ${ }^{3}$ YERIMA, MI \\ ${ }^{I}$ Department of Biological Sciences, Federal University Kashere, Nigeria \\ ${ }^{2}$ Department of Biological Sciences, Yobe State University, Nigeria \\ ${ }^{3}$ Department of Micro Biology Abubakar Tafawa Balewa University, Bauchi, Nigeria
}

\begin{abstract}
Studies were conducted on molluscicidal activities of aqueous extract of leaves stem back and roots of Balanite aegyptiaca against adult Lymnea natalensis, using standard methods. The intermediate host of the helminth Fasciola hepatica. Snail mortalities were compared between each plant part and snail species and $\mathrm{LC}_{50}$ and $\mathrm{LC}_{90}$ values for the plant part tested were recorded. The result obtained showed that the leave extract was more susceptible to the death of snail species Lymnea natalensis. Comparing the $\mathrm{LC}_{50}$ and $\mathrm{LC}_{90}$ the leaves extract showed the highest molluscicidal activity followed by the stem bark and root extracts. Desert date plant shows mollucicidal activities however it is found to be concentration- depended.
\end{abstract}

DOI: https://dx.doi.org/10.4314/jasem.v22i3.21

Copyright: Copyright (ㅇ 2018 Abdullahi et al. This is an open access article distributed under the Creative Commons Attribution License (CCL), which permits unrestricted use, distribution, and reproduction in any medium, provided the original work is properly cited.

Dates: Received: 19 February 2018; Revised: 14 March: 2018; Accepted: 23 March 2018

Keywords; Lymnea natalensis, Fasciola hepatica, Balanite aegyptiaca, Mollucicide, Aqeous extract, Helminth

Balanite egyptica (Del.) Desert date belongs to family Balantiaceae is small tree reaching a height of around $10 \mathrm{~m}$ with compound leaves and greenish yellow flower, and brown or pale brown fruits. It is used as food, fire wood and charcoal, edible fruit and seeds has $30-40 \%$ of edible oil; young foliage fruits are eaten by goats, Sheep and camels; plants parts are used as soap substitutes because of high saponin contents, thorny branches used for fencing Okia, 2010).Widely grown in the Sudano-Sahelian region of Africa, the Middle East and South Asia. It is known by various names, e.g. Arabic names: Heglig (tree), lalob (fruit); trade name: zaccone, zachun, desert date (dried fruit); in India: Hindi name is Hingot and English name is thorn tree/desert date. Traditionally, various parts of B. egyptiaca have been reported to possess medicinal properties in different ethno botanical surveys. It finds its place in the Ayurvedic pharmacopoeia of India and has also been described in some monographs, but none have described the complete traditional uses, phytochemistry and pharmacology of this plant.

Therefore, we have compiled an up-to-date and comprehensive review of B. egyptiaca that covers its traditional uses, phytochemistry and pharmacological properties in this part of Nigeria. According to Sofowora,(1993) The root, stembark, seed kernel, fruit and whole plant extracts were found to be lethal to snails, miracidia and cecaria of schistosomes in various studies In developing countries, they pose a large proportion to public health and contribute to prevalence of malnutrition, aneamia, eosinophilia and pneumonia. Although the majority of infections due to worms are generally limited to tropical regions, they can occur to travelers who visited those areas and some of them can develop in temperature climate, (Hamed, 2010). Parasite infections are an important economic problem of livestock in Nigeria; they reduce productivity and death of producing animals. In small children, Fasciola hepatica is one of the pathogenic worms developing resistance to most of the commercially available anthelminthic which became a severe problem nationwide.

Infectious diseases represent an infectious cause of morbidity and mortality. Parasites have evolved numerous defense mechanisms antiparasitic agents and their resistance to old and newly produced drugs is on increase. A number of studies have been conducted on different plant species of molluscicidal and cercariacidal activities. This study was an attempt to evaluate the potential molluscicidal activities of the plant $B$. egyptiaca against snail intermediate hosts of trematodes, together with the cercariacidal activity against human Fasciola specie in Bauchi setting. The Results of this study provided further information on the use of this plant as 
molluscicidal and cercariacidal agent, particularly in Bauchi. This work is designed to determine phytochemical screening and anthelminthic activity of some parts of Desert date (Balanite egyptica) (Del) against selected helminth (Fasciola hepatica) within Bauchi Metropolis.

\section{MATERIAL AND METHODS}

Collection of Plant Specimen: The parts of the plant desert date Balanite egyptiaca Del., the leaves, stem bark and roots used in this study were collected from Birshin Fulani $1 \mathrm{~km}$ away from the Federal polytechnic Bauchi, Bauchi State. The collected parts were covered with wet sack to avoid sunlight and transported to the A.T.B.U Biology laboratory for analysis.

Collection of Snails: Forty five (45) snail specie Lymnaea natalensis (intermediate host of fascioliasis), were collected from Bayara town and Tashan Mai Alewa respectively situated at the western part of the Federal Polytechnic Bauchi 16km away where irrigation farming is taking place. The snails were collected from the irrigation canals and drainage networks through hand picking method. The snails were placed in a plastic container with a moist soil and grasses; they were then transported to the Biology laboratory for identification and maintenance. The snails were identified and left to acclimatize to laboratory condition before being use in the experiment.

Preparation of Plant Materials: Following collection, the plant parts (leaves, stem bark and roots) were air dried in the laboratory for 5 to 7 days separately (Sofowora, 1993). Therefore, the dried specimens were manually grinded to powdered form using a mortar and pestle. The powdered were sieved using a sieve and the fine material was obtained which was transferred into closed containers until use.

Plants Part Extraction and Phytochemical Screening: A set of soxhlet extractor, thimble, extraction flask and heating mantle was obtained from the laboratory staff and coupled on a retort stand. $50 \mathrm{~g}$ of each portion of the plant material was weighed using a digital weighing balance separately and $350 \mathrm{ml}$ of the solvent hexane was measured using a calibrated measuring cylinder and poured into the flask attached to the soxhlet extractor. The heating mantle, a long rubber tube was attached to the water inlet and outlet of the extractor which helps in cooling the apparatus and moistens the specimen to be extracted while the water was in circulation continuously. The heating mantle was initially set at $40^{\circ} \mathrm{C}$. The solvent started boiling gradually and the temperature was increased to $60^{\circ} \mathrm{C}$ where the steam formed by the solvent penetrates into the specimen contained in the thimble and the extraction begun which accumulate and run through the tubes and flow into the solvent in the flask, the process continued for a time frame of 6 hours and the extraction completed. The above procedure was repeated to the remaining specimens of the sieved stem bark and roots. The liquid extract of the leaves was purely green in colouration, while stem bark and the root extracts were brownish in appearance. The extracts obtained were placed in water bath at $50^{\circ} \mathrm{C}$ where the solvent liberated and left the pure extract. The extract was kept in a conical flask and was covered with a foil paper and kept in a refrigerator until use.

Phytochemical Screening: Phytochemical screening and extraction, and identification of the medicinally active substances found in plants were conducted. Some of the bioactive substances that can be derived from plants are; flavonoids, alkaloids, carotenoids, tannins, antioxidants and phenolic compounds among others.

Test for Tannins was conducted using ferric chloride solution according to Trease and Evans (2002), Steroids using liebermaann buchard test (Sofowora, 1993), Terpenoid using ethanol and acetic anhydride (Sofowora, 1993), Saponins using froth test, Flavonoids using sodium hydroxide test (Trease and Evans (2002), Alkaloids using Meyers reagent (Sofowora, 1993), Phenols using ferric chloride solution and Phytosterols using Salkowski's Test (Salkowski, 2003).

Preparation of the Stock Solution: The concentrations used in these bioassays were prepared from three different parts of desert date Balanite egyptica Del. Leaves, stem bark and roots extracts were prepared in different concentration. The concentration of each extract was prepared in $10 \%$, $20 \%, 30 \%, 40 \%$ and $50 \%$ in distilled water. After determining $100 \%$ motility of the snail specie (Lymnaea natalensis). For each test there was a control with distilled water without plant extract with the same volume of the solution.

Maintenance of the Snails: The snails used in this study were the specie of Lymnaea natalensis. All collected snails were cleaned from the vegetation cover and attached debris by thorough washing of the cowry's shells in clean water. The snails were maintained and fed with spinach and lettuce for their survival in the laboratory 
In Vitro Observation on the lethal effect of Balanite egyptiaca: Five beakers containing 10\%, 20\%, 30\%, $40 \%$ and $50 \%$ extracts of B. aegyptiaca leaves, stem bark and roots were set up in duplicate. To each beaker, 2 freshly snails were inoculated. The motility and mortality status of the snail in each concentration were then observed and recorded at $30 \mathrm{~min}, 1 \mathrm{hr}$, $11 / 12 \mathrm{hr}$ and $2 \mathrm{hr}$ intervals. Results were recorded as very actively motile, actively motile and weakly motile/sluggish. As controls, the same numbers of snails were placed in beakers containing water and set up in duplicates and were observed at similar time intervals for their motility and /or mortality status (Birrie et al., 1998).

Molluscicidal Potency Tests of aqueous Extracts of Balanites egyptiaca against Adult Lymnaea natalensis (snails): The extracts of the plant parts, leaves, stem bark and roots were tested against adult $L$. natalensis snails according to the method recommended by WHO (2003).

Confirmation of the Snails' Death: The deaths of the snails during the tests were confirmed by the change in the shell color and failure of the flesh portion to withdraw into the shell upon mechanical stimuli (probe) or upon gentle application of heat to the shell. Snails were considered dead if they could not move or retracted well into or hanging out of the shell, with the body and shell discolored (Vijay, 2010).

\section{RESULTS AND DISCUSSION}

In the leaves extract, high mortality rate was observed. In $10 \%$ of the leaves extract two snails (2) snails became susceptible upon inoculation and died within 24 hours while in the remaining concentrations of $20 \%, 30 \%, 40 \%$ and $50 \%$ all the three (3) snails were susceptible and died within 24 hours. Low mortality rate was observed, where $10 \%$ of the stem bark extract all the snails were resistant to the extract, in $20 \%$ of the extract only one (1) snail was susceptible and died within 72 hours, while in $30 \%, 40 \%$ and $50 \%$ concentration two (2) snails were susceptible to the extract and died after 48 and 24 hours respectively and 1 snail completely resisted. The aqueous extract of the root of B. egyptica, in
$10 \%$ and $20 \%$ of the extract no susceptibility observed within 24 hours of inoculation. 1 snail was susceptible in $30 \%$ concentration of the extract and 2 snails in each concentration of $40 \%$ and $50 \%$ of the extracts were susceptible and died after 24 hours of inoculation.

The present study showed that aqueous extracts of Balanites egyptiaca leaves extract possess molluscicidal properties. Their activities are time and concentration-dependent. Between the test snail hosts of trematodes, Lymnaea natalensis were more susceptible to the plant extract than aqueous extracts of stem bark followed by root extract which showed the lowest molluscicides within and after 24 hours of exposure period. Previous investigators also reported similar observations by Vijay, (2010); El-Sheihk, (1994); (Adewunmi and Sofowora, 1980).

The varying potencies of each plant part may be due to the differences in the concentration and/or the type of the active ingredient(s) present in each part Brimer et al., (2007). In this observation, water extracts of leaves and stem bark were more potent than the water extract of roots, due to the more concentrations of saponins in the leaves, and also presence of high amount of steroids in the stem bark and root Bah et al., 2006; Brimer et al., (2007). Therefore, the presence of these two ingredients in the aforementioned plant parts could be the most probable reason for the high molluscicidal property of leaves over the stem bark and roots. The molluscicidal activity of aqueous extracts of leaves, stem bark and roots of $B$. aegyptiaca against adult Lymnaea natalensis was investigated and the concentration dependent. Generally, mortality of Lymnaea natalensis increased with increase in extracts' concentrations (Tables 2-4). The lethal concentrations for aqueous extracts of Balanites egyptiaca leaves, stem bark and the root extracts that killed $90 \%\left(\mathrm{LC}_{90}\right)$ of adult Lymnaea natalensis was, $10 \%$ concentration of the extract, $20 \%, 30 \%, 40 \%$ and $50 \%$ killed 100 all the snails respectively. Comparing the $\mathrm{LC}_{50}$ and $\mathrm{LC}_{90}$ of the plant parts, leaves showed the highest molluscicidal activity, followed by stem bark and root extracts.

Table 1: Phytochemical Screening of the Three Different Parts of the Plant B. Aegyptica, Leaves, Stem Bark and Roots

\begin{tabular}{lllllllll}
\hline Samples & TNN & FLV & PHS & STE & ALK & PHE & SPN & TRP \\
\hline Leaves & + & + & - & - & + & - & +++ & - \\
Stem bark & + & + & + & ++ & + & + & - & - \\
Roots & + & + & + & + & + & + & - & - \\
\hline
\end{tabular}

Keys:-Negative result (parameter not observed in the extract); + Minimum colour/precipitate intensity; ++ Medium colour/precipitate intensity; +++ High colour/precipiate intensity; TNN= Tanin, FLV= Flavonin, PHS= Phytosterols, STE = steroids, ALK= Alkaloids, $P H E=$ Phenols, SPN= Saponins and TRP= Terpenoids. 
Molluscicidal Activity of Aqueous Extract.....

Also, in the roots specimen, Tannins, Flavonoids, Sterols, and Phenols were positive with a minimum colour/precipitate indicated by (+), while Steroids were positive with medium colour/precipitate indicated with (++), Alkaloid and Phenols were negative (-) which shows no parameter observed.

Table 2: molluscicidal potency of aqueous extract of balanites egyptiaca leaves extract on mortality rates of lymnaea natalensis

\begin{tabular}{ccccc}
\hline $\begin{array}{c}\text { Inoculation } \\
\text { time(hours) }\end{array}$ & $\begin{array}{c}\text { Conc. of the } \\
\text { extract }(\boldsymbol{\%})\end{array}$ & $\begin{array}{c}\text { Number of } \\
\text { tested snails }\end{array}$ & $\begin{array}{c}\text { Number of } \\
\text { dead snails }\end{array}$ & $\begin{array}{c}\text { Mortality rate } \\
(\boldsymbol{\%})\end{array}$ \\
\hline 24 & 10 & 3 & 2 & 66.67 \\
24 & 20 & 3 & 3 & 100 \\
24 & 30 & 3 & 3 & 100 \\
24 & 40 & 3 & 3 & 100 \\
24 & 50 & 3 & 3 & 100 \\
\hline
\end{tabular}

Table 3: Molluscicidal potency of aqueous extract of balanites egyptiaca stem bark on mortality rates of lymnaea natalensis

\begin{tabular}{ccccc}
\hline $\begin{array}{c}\text { Inoculation } \\
\text { time(hours) }\end{array}$ & $\begin{array}{c}\text { Conc. of the } \\
\text { extract (\%) }\end{array}$ & $\begin{array}{c}\text { Number of } \\
\text { tested snails }\end{array}$ & $\begin{array}{c}\text { Number of } \\
\text { dead snails }\end{array}$ & $\begin{array}{c}\text { Mortality } \\
\text { rate (\%) }\end{array}$ \\
\hline 72 & 10 & 3 & 0 & 0 \\
72 & 20 & 3 & 1 & 33.33 \\
48 & 30 & 3 & 2 & 66.67 \\
24 & 40 & 3 & 2 & 66.67 \\
24 & 50 & 3 & 2 & 66.67 \\
\hline
\end{tabular}

Table 4: Molluscicidal potency of aqueous extract of balanites egyptiaca roots extract on mortality rates of lymnaea natalensis

\begin{tabular}{ccccc}
\hline $\begin{array}{c}\text { Inoculation } \\
\text { time(hours) }\end{array}$ & $\begin{array}{c}\text { Conc. of the } \\
\text { extract }(\%)\end{array}$ & $\begin{array}{c}\text { Number of } \\
\text { tested snails }\end{array}$ & $\begin{array}{c}\text { Number of } \\
\text { dead snails }\end{array}$ & $\begin{array}{c}\text { Mortality } \\
\text { rate (\%) }\end{array}$ \\
\hline 24 & 10 & 3 & 0 & 0 \\
48 & 20 & 3 & 1 & 33.33 \\
48 & 30 & 3 & 1 & 33.33 \\
72 & 40 & 3 & 2 & 66.67 \\
72 & 50 & 3 & 2 & 66.67 \\
\hline
\end{tabular}

Comparison of the $\mathrm{LC}_{50}$ and $\mathrm{LC}_{90}$ values of the leaves, stem bark and root extracts of $B$. aegyptiacaagainst the snail species showed that $L$. natalensis were susceptible to leaves extract of the plant. Both $\mathrm{LC}_{50}$ and $\mathrm{LC}_{90}$ values obtained for the leaves extract were significant against $L$. natalensis. With regards to the snail species, the snails were more susceptible to the leaves extract. No difference of molluscicidal activity was observed with respect to plant and snail collection sites.

No mortality was observed in the snails inoculated in the stem bark and the roots extracts for the first three hours, until after 24 hours that the snails were observed to be sluggish and died within 28 hours, this is in line with the studies made by Shekhawat and Vijayvergia (2010) who studied the molluscicidal activity of this plant and found out that B. egyptiaca saponins (leaves) produced significant effect on Bulinus truncates at different concentrations. They also observed that the mortality of snails increased with increasing concentration and exposure period. In addition, Ndabaneze et al. (1994) observed that $B$. aegyptiaca leaves exhibited greatest toxicity at $10 \mathrm{mg}$ of powder/liter and $100 \%$ mortality at $100 \mathrm{mg} / \mathrm{l}$. The present observation on $B$. aegyptiaca against Biomphalaria pfeifferi (100\% mortality at $100 \mathrm{mg} / \mathrm{l}$ in both roots and stem bark) was similar with the findings of Ndabaneze et al. (1994) But the results obtained for L. natalensis do not agree with their result with $100 \%$ mortality at a concentration of 120 $\mathrm{mg} / \mathrm{l}$ in both the stem bark and roots.

Conclusion: From the present study, it can be concluded that aqueous extracts of leaves stem and roots of Balanites egyptiaca have reasonable molluscicidal activity. Different parts of the plant showed different level of molluscicidal potencies. The aqueous extract of leaves exhibited stronger molluscicidal activity compared to the stem-back and root.

\section{REFERENCE}

Adewunmi, C O; Sofowora, E. A. (1980) Preliminary screening of some plant extracts for molluscicidal activity. Planta. Med. 39: 57-65.

Brimer, L; Elsheik, S; Furu, P. (2007) Preliminary investigation of the disposition of the molluscicidal saponindeltonin from Balanites egyptiaca in a snail species.

Bah, S; Diallo, D; Dembélé, S; and Paulsen, B. (2006) Ethnopharmacological survey of plants used for the treatment of schistosomiasis in Niono District, Mali. J. Ethnopharmacol. 105: 387-399.

Birrie, H; Balcha, F; Erko, B; Bezuneh, A; Gemeda, N. (1998). Investigation into the cercariacidal 
and miracidiacidal properties of Endod (Phytolacca dodecandra) berries (type 44). East Afr. Med J 75: 311-314.

El-Sheikh, S. H. (1994) Biological and Chemical Studies on Molluscicidal and Schistosomicidal Compounds with Special Reference to Balanites egyptiaca (L) Del. Constituents. Ph.D. Thesis, University of Khartoum, Khartoum. Pp 112-120

Hamed, M. A. (2010).Strategic control of schistosome intermediate host. Asian $J$. Epidemiol 3: 123-14

.Ndabaneze, P; Engels, D; Kavamahanga, P (1994).Study of the effects of plant molluscicides flora of Burundi on Biomphalaria pfeifferi, the intermediate host of Biliharzia. In: Proceedings of the 14th AETFAT Congress, $\mathrm{Pp}$. 757- 760, (Vander, M., Burgt, X. and Rooy, M., eds). Kluwer Academic Publishers.

Salkowski, C. K. (2003) A text Book of Practical pharmacognosy. $5^{\text {th }}$ Ed., VallabhPrakashan New Delhi: 107-111.

Sofowora, E A; Evans T. (1993) Medicinal Plants and traditional medicine in Africa. Spectrum Books Limited Ibadan Nigeria, pp 191-289.

Shekhawat, N; and Vijayvergia, R; (2010).Molluscicidal activity of some Indian medicinal plants against the snail Lymnaea acuminata and in the control of fascioliasis. $J$. Herbs Med. Toxicol. 4: 109-112.
Tilahun, G; Ali, A; Eshete, H; Abebe, I; Kloos, H (1998) Prevention of schistosomiasis. In: Schistosomiasis in Ethiopia and Eritrea, pp. 148162

Okia, C (2010) Balanites aegyptiaca: A resource for Improving Nutrition and Income of Dryland Communities in Uganda PhD thesis Uganda pp 216

Vijay, P. (2010). Evaluation of molluscicidal activity of some Indian medicinal plants against Lymnaea acuminate. Inter. J. Appl. Biol. Pharm Technol. 1: 308-311.

WHO (1983). Report of Scientific Working Group on Plant Molluscicide and Guidelines for Evaluation of Plant Molluscicide, (TDR/SCH - SWE (4)/ 83.3), Geneva.

WHO (1984). The Controls of schistosomiasis. World Health Organization, Geneva.

WHO (1993). The control of schistosomiasis. Report of the WHO Expert Committee, Geneva.

WHO (2003). The control of schistosomiasis. 2nd report of the WHO Expert Committee, Geneva.

WHO (2007). Report of the WHO Informal Meeting on use of triclabendazole in Human and .Ruminants Animals.

WHO (2009). Informal Consultation. WHO/HTM/NTD/PCT/2009. 